\title{
The product manager in the artificial intelligence world
}

\author{
Manjeet Singh \\ ServiceNow \\ e-mail: manjeet.singh@servicenow.com
}

\begin{abstract}
Cloud applications, artificial intelligence, machine learning, data insights, rapid prototyping, design thinking, and faster decision making are becoming more and more significant in the daily life of the product manager. Basic physical, digital, and biological technologies are intersecting to create large scale system changes, altering the very fabric of our social system. More than ever, the product manager is faced with the challenges of proactively designing the systems of the future. This study will deal with the question: how can the product manager thrive in an artificial intelligence machine learning world?. With the advancement in machine learning, products can now significantly differ from the traditional style of product designs. One widely known example is how Google answers our questions with the best possible answers through ranking. Similarly, Netflix or Spotify suggest media to customers using the process of recommending, giving users things they may be interested in, without them explicitly searching. On the other hand, Gmail groups an email as spam or not spam through classifying. With these many possibilities, today's product manager must understand the actual problem that must be solved to grow customer value systems in line with the company's goals. And while product managers inspire through vision, decisions must roll downstream and be implementation-based like an assembly line. More than ever, it has become crucial for a product manager to set and manage the anticipations of users, gather measurable feedback frequently, communicate meticulously to engineers, and make sure products logically progress with market shifts.
\end{abstract}

Keywords: product manager, artificial intelligence, learning machine.

\section{Introduction}

Men and machines have to go together, come to terms and rule the world. When we were young, we played with simple machines. Now that we are men and women, who are players in this game of providing goods and services, we still play with machines, complex machines that are evolving to feel and think like us. In the course of this study, game can be interchanged with competition, a competition between man and machine. Machine and machine learning challenge human's way of thinking.

During World War II, machines that people played were used for war and death, but now information technology and cybernetics are used to save and prolong life (JOHNSTON, 2010). Machine and machine learning are now tools to compete in business, to enlarge wealth and create behemoths of businesses. Look at Google, Apple, Facebook, Twitter, Amazon, and all the other technology companies that were once retailer of goods. They built stores and large warehouses but now they use computers and information technology to enlarge their businesses. Never mind those warehouses and those large physical stores. What is important is a state-of-the-art website that can showcase the essence and size of the company. That is where customers examine, interact and make judgment about the growth and strength of the company.

This study will deal with the question: how can the product manager thrive in an AI and machine learning world? This is also about artificial intelligence (AI) and machine learning (ML) and its impact on business and the product manager. With the exponential rate of change in technology in recent decades, the role of the product manager has evolved and expanded drastically. The structure of every industry is being transformed, and each one of us is interacting with technology in new ways, from giving voice commands to virtual assistants to having smart replies that suggest quick responses to our messages.

\section{Methodology}

First, this paper had to dig into the voluminous literature in the world of the manager, and the simple but complex world of the artificial intelligence and its impact on industry and product management. Research was conducted on books, journals and articles from various databases, like PROQuest, EBSCO, and other online databases, including websites that can provide important information and contexts regarding the so-called competition between 
human perception and artificial intelligence. Who wins or who has the edge is not the concern of this study but who might be benefited, or affected, in the popularity and advancement of artificial intelligence, machine learning and deep learning in business and industry is the main concern of this research. This study will first conduct a literature review of the subjects mentioned, and then an analysis will follow to arrive at a possible conclusion and recommendation.

\section{Theorical background}

\subsection{Product management}

The business environment is more dynamic than before. There are many forces that affect product management, such as technologies, globalization, supply chain management, consumer wants and needs, and many more. Technology can help the product manager adapt to these dynamisms. But the principles of management and marketing still apply in adapting to the changes (NĚMEC; WROBLOWSKA, 2018). Kotler and Keller (as cited in Němec; Wroblowska, 2018 , p. 128) argue that product management should be an added department to the organization and not "replace a functional organisation"

\subsection{Artificial intelligence}

In talking about AI, people usually think about machines and robotics, "[...] ubiquitous computing and interfacing technology, artificial life and multiagent systems, and evolutionary robotics [...]" (PFEIFER et al., 2006, p. 26). There are myths and also truths about AI and it is also always misunderstood. AI was invented many years ago, even during the olden times. This has been with us for so long but which ordinary individuals have never known in the course of doing the ordinary activities of life, except in movies when they are entertained. Thus, this is what makes AI a topic of entertainment, simply because it is interesting and "dream-like" or fantasy-like.

Artificial intelligence is a branch of computer science that "focuses on machines that learn" (FRANK et al., 2017 p. 48). AI is defined by its function, which means "the system actually makes the decision" (BOOBIER, 2018, p. 37), because AI can formulate hypotheses, conduct diagnoses, recommend treatments (BAILEY et al., 2018). AI makes a machine "make itself" and with machine-learning software, they improve over time. General or "strong" AI is the long dream of researchers because it is about having "the same general intelligence as a human" (FRANK et al., 2017, p. 49).

How does AI work? Intelligence is brought to life with "[...] software that learns, massive processing power, and enormous amounts of data [...]" (FRANK et al., 2017, p. 47). That will make an enormous amount of intelligence. AI applications use the rule-based system (if-then statements, such as, IF “A," THEN “B”). The traditional AI used simpler IF-THEN, but the problem of rule-based is that it can be awkward (PRADEEP et al., 2018). The new rule-based AI uses several suppositions and conclusions. ML does not use key words as it focuses on the outcomes (PRADEEP et al., 2018). This is brought about by the wonders of algorithm, which provides a learning process as the machine continues with the task. There is also the inference engine which uses "automatic rule inference," or logic, to arrive at future outcomes. A ML system has a database to collect facts and data, an inference engine that interprets data, and a user interface that provides user interaction (PRADEEP et al., 2018).

AI can help humans (the manager, for instance) through more information and ideas in order to reach timely and good decisions, and replace human work with robotics. According to Boobier (2018), it is easier to augment with AI, but to automate means risks of job loss and livelihood. However, as mentioned elsewhere, job losses can also be addressed with job creation. Still, a percentage of the labor force has to suffer, or they have to find a new skill or a new job.

\subsection{Current state and latest trends}

Artificial intelligence has invaded people's homes, businesses and offices. Almost everything is being done by machines, while they make our days easier and fun (FRANK et al., 2017). But it is never fun for the product manager as he/she thinks of what to do and not to do and expects of the next AI thing to come into the manufacturing plant next time. When machines do everything, what happens to the product manager? Will AI and machine learning greatly affect the job of the product manager? For the common laborer, yes, but for the PM, AI will help make the job easier. Machine learning is good for detecting spam and junk emails. But this still needs human help (BELL, 2014). If it is for product designing, or manufacturing, the job of the product manager is never lost.

The product manager has a role to make a cross-functional decision, bring different teams together, make a trade-off decision and ensure the alignment of diverse functions. This duty has led to the influx of more companies outside of the traditional technology sector into the digital area as they now set out to build software capabilities for the success of the products. As most products now are becoming user-friendly and permeate each of our lives and business, the modern product managers are now expected to know their customers intimately and their preferences. Companies now expect a better experience for enterprise software.

\subsection{Al and Machine Learning (ML)}

A recent analysis by McKinsey identified three common types of PMs: technologists, generalists, and business-oriented. New product managers should be 
technology- and business-oriented, with a penchant for innovation. Product management in this century will be defined by its bottom-up process. The product manager not only just addresses problems with their team; the PM predicts desires and always works with the bigger picture. The modern product manager should comprehend their customers and their preferences intimately. This is done through shadowing exercises, one-on-one interviews, questionnaire distribution, and online channels in order to observe, interact with, and understand how people use and experience the products. With artificial intelligence and machine learning, product managers now have an avalanche of data at their disposal to make data driven decisions with elegant solutions. With more data, measuring the success of a product introduction in the market should follow a broader set of metrics through deep learning. This measurement includes engagement, conversion, retention, at more significant levels, giving the product manager more latitude, control, and widespread influence.

The bottom-up approach involves constant changes to prototypes in determining patterns. When directing teams, the product manager must ensure that all processes are accounted for and done so through organic collaboration and brainstorming with the data science, engineering, and user experience staff. The dynamic nature of artificial intelligence and machine learning compels teams to work together as a group and share a common goal.

\section{The contemporary product management practice}

In product creation, the product manager gathers information from real-world feedback before deciding on what to produce. The product manager (PM) should be good at theory and apply it on practice, and understand the actual problem in the product creation while concentrating on the customer's value system in line with the company's goals. The team will set out in developing the prioritized features of the product, after which designers will come up with mockups while waiting for the engineers in building the features to jump in. While product managers inspire through vision, decisions roll downstream and tend to be more implementation based. It is important for the PM to set and manage the anticipations of users, gather measurable feedback frequently, communicate meticulously with engineers, and make sure the product logically progresses with the business and market shifts (AMMAR; ABDELMOEZ; HAMDI, 2012).

\section{I. Moving from the analytics to Al and ML}

The modern product manager's skillsets should be unique (Figure 1). Below is a playbook on how to think and successfully adapt artificial intelligence and machine learning to the team.

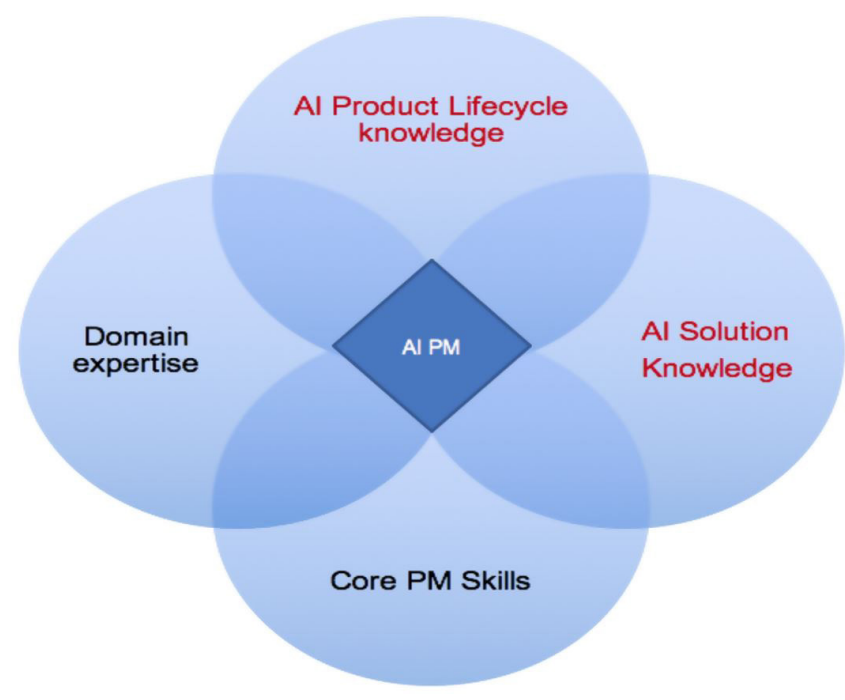

Figure 1. Product manager skills in the artificial intelligence era.

\section{Get the data right}

The most fundamental step for the product manager is to look at the problem space and then collect and collate vital data sources. Recognize patterns in the generated data and also seek to continuously develop sources of data to improve on the product (AMMAR; ABDELMOEZ; HAMDI, 2012).

\section{Assess opportunities}

Look out for the most significant improvements needed. This is related to the first step, as collecting the correct data will allow the product manager to make use of the data (RECH; ALTHOFF, 2004). Most collected data are deficient in bias. Like a seasoned CEO, the modern product manager should spot faulty data, and work with the correct personnel and data engineers to resolve and interpret it. This data will in turn be used to assess opportunities.

\section{Prepare for the worst}

An astute product manager takes time to weigh all the likely scenarios that will take place. This is done using the game theory system. Make sure to weigh the cost of getting something wrong. It's important for the product manager to understand fully what errors look like and how this might affect the user's experience of the product, along with ways to quickly adjust to errors. This includes incorporating AI and ML to understand errors related to human behavior.

\section{Be open to feedback}

A company grows through improvement, and similarly, prioritizing feedback loops is essential for the product manager. Safety nets and feedback loop, as stated by Meziane and Vadera (2012), are visible to the user and 
also take into account that an incorrect and flawed product created has its consequences. With the aid of the feedback loop and a safety net, the product manager can now monitor, evaluate, and build future decisions for artificial intelligence and machine learning in product development.

Artificial intelligence, machine learning, deep learning - these are moving forward in leaps and bounds (presently, some researchers now speak of developing artificial superintelligence-ASI) and much of the enthusiasm about $\mathrm{AI}$ and $\mathrm{ML}$ is directed toward applications and software that will allow computer systems to operate with considerable freedom. The new self-driving car now used in China is the poster child for $\mathrm{AI}$ and machine learning, but there are other enthralling applications - ranging from robotic clinicians who with the aid of artificial intelligence and machine learning are now able to diagnose complicated illnesses more accurately than any human doctor to AI-directed corporations and incorporated product manager that can coordinate company activities without flesh-and-blood management.

With smarter AI, the product manager's role is more of a supervisory position, but what is there to supervise? For example, the RIKEN Center for Advanced Intelligence reported that they have developed a smarter AI without negative data, giving machine learning more preferable than human supervision (BYRUM, 2019). AI is not a threat but an opportunity for the product manager, for marketers, and for the entire business. Applications such as speech recognition, speaker verification, spam or fraud detection, are all tools that will help the world of the PM become easier and challenging (PRADEEP; APPEL; STHANUNATHAN, 2018).

\subsection{Uses of $M L$}

According to Bell (2014), machine learning can be used for software application, where the machine learns about the user and predicts about user wants in the course of time. One of the applications made by Apple is Siri, which recognizes voice and answers questions of the user (BELL, 2014). On the other hand, deep learning is a development of ML. Amit Karp (2018) says that deep learning "relies on simulating large multilayered webs of virtual neurons," which makes a computer more intelligent by deciphering abstract patterns and help humans solve difficult problems. In other words, deep learning makes the machine more sophisticated in helping humans perform tasks. But that does not mean it has won the competition versus the human brain and thinking. The question of who is in control still falls on the human side.

Machine learning can also be used for healthcare analytics. Healthcare professionals can now access big data and quality data and use this for decision making. Doctors can get the information they need from millions of pages of medical research and other important information of evidence-based practice. Using smartphones, users can regularly access information about their health (BELL, 2014). Machine learning has been applied in oncology and mining Electronic Health Records (EHRs) (BAILEY; ALLISON; PEARSON, 2018). Decision tree learning is also used in making medical diagnoses in some cancer cases or congenital heart disease (Kumar \& Kalra as cited in BAILEY et al., 2018). Smart medicine that leads to precision medicine has been the focus of Wun-Jae's (2018) study. Precision medicine is defined as " $[\ldots]$ an innovative approach that takes into account each individual's different characteristics, such as genetic profile environment, and lifestyle [...]" (WUN-JAE, 2018, p. 69).

\section{Improving customer experience with new technologies}

\subsection{Blockchain}

Swan (2015) refers to blockchain as a public ledger which can become a worldwide record for the registration and transfer of all tangible and intangible assets. This records the cryptocurrency or bitcoin, also known as digital cash used for the purchase of products and services over the internet. A person who makes use of a bitcoin will need to register in a wallet software, and with his/her personal details. One needs to know the private key to an address before he/she can access the bitcoin, which has to be done using the internet. This can lead to a new economy, without the hustle and bustle of owning local currencies or dollars (SWAN, 2015).

\subsection{Chatbots}

Chatbots are software applications that can communicate through natural language (Dale as cited in Skjuve et al., 2019). Microsoft and Facebook customers are excited to use chatbots in messaging. Alibaba and Domino Pizza have used this to help customers. Some chatbots have unique roles, for example, Mitsuku or Replika are programmed as social companions, while Woebot and Wysa have vast information about mental health. Duolingo and Mondly are experts in language acquisition. With advancement in AI, chatbots can now mimic human behavior, and in the future it would be difficult to determine between chatbot or human conversation (SKJUVE et al., 2019).

\subsection{Internet of Things (loT) chatbots}

To connect objects and humans wherever they may be, $24 / 7$, is the aim of the Internet of Things (IoT), which refers to the innumerable software applications and protocols, with computer networks and mobile devices connecting objects and people. According to Khodadadi et al. (2016), a utopia is being created in that everyone can talk to a business associate, a loved one, or other unknown people 
who might be in the other side of the globe, using the internet and mobile device. There are two words that strike us in understanding this growing phenomenon: "internet" and "things". In the words of Khodadadi et al. (2016, p. 3), this covers "[...] a more generic set of entities, able to communicate with other entities, making it accessible at any time, anywhere [...]". The role of the product manager in the IoT world might be complex but he/she has to adjust to this complex interconnected world. The different divisions of the organization are connected and the PM has access to the internal and external environment. In the same manner, the external world also has access to the internal branches of the organization (KHODADADI et al., 2016).

AI is a tool for humanity's advancement, and enables effective reasoning, thinking and learning in the art of computing (ANDERSON; JIANG, 2018). It enhances human capabilities in the field of medical diagnoses, weather forecasting, supply chain management, transportation, to name a few (ATKINSON, 2018). It is commonly used by millennials, young generation who use smartphones in their daily activities and studies. $95 \%$ of U.S. teenagers surveyed by Pew Research Center reported that they use smartphones, almost half of the survey participants said they were connected most of the time, and their favorite social media sites were YouTube, Instagram and Snapchat. Facebook rank behind the three social media platforms (ANDERSON; JIANG, 2018). AI has made the lives of people, young and old, better and more fun. Every Facebook or Twitter post, every application, blog, email, each recorded incident, every contract - is significant data that can become part of a repository or a database. According to Siegel (2016), it can grow to as much as 2.5 quintillion bytes that only a computer could hold. And they can be a raw material for a product of a technological company (SIEGEL, 2016). Atkinson (2018) recommends that policymakers should help in its propagation. What is the outcome if this is not done? Growth in the per-capita incomes of nations will suffer, to include progress in health and improvement of goods and services. The myths about AI are instigated by panic in thinking that nonhumans might be able to overcome or conquer us (like in the "War of the Worlds?" or the Terminator). Another cause of those false beliefs is the fact that $\mathrm{AI}$ is complicated and might destroy that long-kept privacy. Documentarian James Barrat (as cited in Atkinson, 2018) asserts that we should trust our perceptions instead of having fears that $\mathrm{AI}$ is more intelligent than people, because it is simply not.

\subsection{The printer revolution}

Can machines reproduce themselves? And what would be the role of the PM? These are questions that have intrigued authors and scientists. Machines that reproduce themselves can make everlasting products. Take this: the PM and automata, or the age of the new AI. The automata can be complex but we now have the $3 \mathrm{D}$ printer which is being perfected to produce a live human organ. In Japan, a tiny fetus has been $3 \mathrm{D}$ printed to create a replica of the fetus as commemoration of a mother's first ultrasound (LIPSON; KURMAN, 2013). After information revolution, we have the revolution of the $3 \mathrm{D}$ printing machine, which can print almost everything. This will revolutionize manufacturing and might violate every intellectual property law (LIPSON; KURMAN, 2013). The 3D printer will have a significant role in creation of products. Before a product will reach manufacturing, this has to be properly designed using a 3D prototype. The PM and the engineers will collaborate to create an almost perfect prototype. Then, it will go to manufacturing. One example is the collaboration of Dassault Systems and Morphosis, which provide a new system of design where "drawing, digital, information, data and modeling in general" are integrated in a process to produce an architecture based on experience, aided with the latest technology could offer - a parametric software applied with 3DEXPERIENCE (DASSAULT..., 2019).

\subsection{Key takeaways}

Every opportunity has risks. An Oxford University study says that by 2025 , millions of U.S. jobs will be lost due to automation. Across the G7 industrialized countries, at least 173 million jobs are at risk within eight years, due to automation (FRANK et al., 2017). However, the surveys could be exaggerated and might not be the dim scenario that was predicted. Frank et al. (2017) argue that only about $12 \%$ of the jobs might be automated, which is equivalent to about 19 million jobs in the U.S. Automation will also change the G7 labor force: $12 \%$ of existing jobs will be at risk, a great portion of the jobs (75\%) is altered or enhanced, but about $13 \%$ will be created. On the other hand, McKinsey\&Co reported that only $5 \%$ of jobs can be lost while automation will cover $60 \%$ of the jobs (NĚMEC; WROBLOWSKA, 2018). Manual labor is still important and can be interchanged with knowledge labor. Technology destroys jobs but also creates new jobs, and time has to be considered in making predictions about ML (FRANK et al., 2017).

\section{Conclusion}

There are some instances that smart technology might outperform humans in some tasks - but not all. Humans still dominate the thinking and business operations and outperform technology on highly complex tasks. But the way smart technology has performed these past two decades will tell that there is an ongoing competition. For example, University of Alberta's Chinook program outperformed Marion Tinsley in a checker player in 1994; IBM's Deep Blue beat chess grandmaster Garry Kasparov, and so on. It is fair to say then that for the next two decades or so, there will be more difficult tasks for smart technology to solve 
and accomplish (BYRUM, 2019). But it has not come to the point that computers understand the way humans do, as what Bill Gates asked when interviewed on Reddit. It may come to that point - a Super AI (FRANK et al., 2017), but humans are still in control. It is for real and not what we see in and understand from the movies - the celluloid world is not for real but for make-believe.

Moreover, do we have to depend solely on machines? If we do not rely on machines, then we can switch back to the traditional way. But is that not the primitive way - going backward? Why not ask the computer to find ways instead of discarding it and going back to the olden times? Those are suppositions - and beliefs that are not true. Turning back the hands of time might be catastrophic. Rather, why not look forward to the future? As mentioned in the early part of this paper, humans and machine should go together. Let us not make the world of the product manager difficult. There should be collaboration and not competition. This is what is going on in the business world and product management - a collaboration between humans and machine. This will make our world a better place to live in.

\section{References}

AMMAR, H.; ABDELMOEZ, W.; HAMDI, M. S. Software engineering using artificial intelligence techniques: current state and open problems. Mississauga: Institute of Communication, Culture, Information, and Technology, University of Toronto, 2012.

ANDERSON, M.; JIANG, J. Teens, social media \& technology 2018. 2018. Available from: <https:// www.pewinternet.org/2018/05/31/teens-social-mediatechnology-2018/>. Access in: 31 May 2018.

ATKINSON, R. "It is going to kill us!" and other myths about the future of artificial intelligence. IUP Journal of Computer Sciences, v. 12, n. 4, p. 7-56, 2018.

BAILEY, G.; ALLISON, J.; PEARSON, M. A comparison of machine learning applications across professional sectors. IUP Journal of Information Technology, v. 14, n. 4, p. 7-20, 2018. http://dx.doi.org/10.2139/ssrn.3174123.

BELL, J. Machine learning: hands-on for developers and technical professionals. New Jersey: John Wiley \& Sons, Inc., 2014.

BOOBIER, T. Advanced analytics and AI: impact, implementation, and the future of work. West Sussex: John Wiley \& Sons, Inc., 2018.

BYRUM, J. Engineering the intelligent enterprise: augmented intelligence can't match human thinking but can optimize business processes. ISE: Industrial \& Systems Engineering at Work, v. 51, n. 1, p. 40-43, 2019.

DASSAULT SYSTEMS. Morphosis experience. 2019. Available from: <https://trends-events.3ds.com/design/ content/morphosis-experience>. Access in: 03 Oct 2019.
FRANK, M.; ROEHRIG, P.; PRING, B. What to do when machines do everything: how to get ahead in a world of AI, algorithms, BOTS, and big data. Hoboken: John Wiley \& Sons, Inc., 2017.

JOHNSTON, J. The allure of machinic life: cybernetics, artificial life, and the new AI. Cambridge: MIT Press, 2010.

KARP, A. Deep learning will be huge - and here's who will dominate it. 2018. Available from: <https://venturebeat. com/2016/04/02/deep-learning-will-be-huge-and-hereswho-will-dominate-it/>. Access in: 04 Feb 2016

KHODADADI, F.; DASTJERDI, A.; BUYYA, R. Internet of things: an overview. In: DASTJERDI, A.; BUYYA, R. Internet of things: principles and pradigms. Cambridge: Elsevier Science \& Technology, 2016. p. 3-27.

LIPSON, H.; KURMAN, M. Fabricated: the new world of 3D printing. Indianapolis: John Wiley \& Sons, Inc., 2013.

MEZIANE, F.; VADERA, S. Artificial intelligence in software engineering: current developments and future prospects. Pensilvânia: IGI Global Disseminator of Knowledge, 2012.

NĚMEC, O.; WROBLOWSKA, Z. Requirements for applicants for the position of "product manager" in the USA. ACTA VŠFS, v. 12, n. 2, p. 125-139, 2018.

PFEIFER, R.; BONGARD, J.; GRAND, S. How the body shapes the way we think: a new view of intelligence. Cambridge: MIT Press, 2006.

PRADEEP, A.; APPEL, A.; STHANUNATHAN, S. AI for marketing and product innovation: powerful new tools for predicting trends, connecting with customers, and closing sales. New Jersey: John Wiley \& Sons, Inc., 2018.

RECH, J.; ALTHOFF, K. Artificial intelligence (AI) and Software Engineering (SE): status and future trends. Germany: Dr. Jorg Rech, 2004. v. 18, p. 5-11. Available from: <http://joerg-rech.com/Paper/Rech_KI_AI-SESurvey.pdf $>$. Access in: day month year.

SIEGEL, E. Predictive analytics: the power to predict who will click, buy, lie, or die. New Jersey: John Wiley \& Sons, Inc., 2016.

SKJUVE, M. et al. Help! Is my chatbot falling into the uncanny valley? An empirical study of user experience in humanchatbot interaction. Human Technology, v. 15, n. 1, p. 30-54, 2019.

SWAN, M. Blockchain: blueprint for a new economy. Cambridge: O’Reilly Media, Incorporated, 2015.

WUN-JAE, K. Knowledge-based diagnosis and prediction using big data and deep learning in precision medicine. Investigative and Clinical Urology, v. 59, n. 2, p. 69-71, 2018. 